\title{
ブロックチェーンの データ構造と動作原理
}

小出俊夫 Toshio Koide NECセキュリティ研究所

\section{はじめに}

「ブロックチェーン」が何を意味しているかは，人に より大きく異なるだろう。ブロックと称するデータの 「かたまり」がチェーン状につながつたデー夕構造のこ とや，そのデー夕構造を維持する分散システムのことか もしれない。はたまた，デー夕を改ざんできない魔法の ようなデータベースや，世の中を大変革してしまう技術 のことかもしれない。ここではそのどれが正解であるか は追求しないが，少なくともブロックチェーンという用 語を有名にした「ビットコイン」の目的を通して，その 意味の輪郭をつかみ取ることはできるだろう。

ビットコインは，インターネット上の支払いシステム である、「サトシ・ナカモト」と称する人物が，ある暗 号関係のメーリングリストで発表 ${ }^{(1)}$ した論文 ${ }^{(2)}$ のアイ デアを元に有志が実装し，2009 年 1 月から現在まで動 作し続けている.

ビットコインの目的は，第三者を介さずにインター ネット上の支払いを可能にすることである．第三者とは 例えば銀行に代表される金融機関が該当する．金融機関 は不特定多数との取引を安心して行えるよう信用の維持 と利用者の保護を図る必要があり，日本では金融庁や財 務局の免許や許可の下でサービスを提供している。その 安心と引換えに，ルール遵守や信用維持には少なくない コストが掛かっており，厳重な本人確認や送金額の制 限, 各種手数料の高さなどとなって現れてくる.

ビットコインの主な貢献は，皆が第三者を必要とせず にネットワーク全体を信用する状況を作り出す，トラス トレス（trustless）の分散型信用基盤を実現したことに ある。これによって，第三者の制約を受けずに誰でも (IoT 機器や $\mathrm{AI}$ など人間以外も) 口座を持ち，世界をま たがり自由に安心して送金できる状況を作り出した。そ の一方で，例えばエネルギー効率やトランザクション性 能は従来の分散データベースと比較にならないほど劣っ
ている.

しかしその貢献には，性能の悪さをカバーするのに十 分なインパクトがある.ビットコインやブロックチェー ンが注目される理由は，信用の源泉が変化し様々な発展 性と可能性をもたらす社会的インパクトと，それを実現 させる技術的インパクトと，投機対象として魅力的価值 を持つに至った経済的インパクトが背景にあるとみてよ いだろう。

例えば，国籍不明のロボットがインターネット上で自 律的にお金を稼ぎ，本人の証明ができず銀行口座を開け ない難民の子供たちへ，直接，国際送金して寄付をする ことも可能になる，更に，ビットコインでは送金を権利 移転として表現するので，これを一般化し，特許，著作 権，登記などの権利管理に広げれば，関連する団体や組 織といった第三者をプログラムに置き換えて自動化・無 国籍化する可能性もある。 また，裏付けを持たない単な るビット列が価值を持ち，投機の対象となった事実も驚 嘆に值する。

ビットコインの一般的な技術の解説は文献（3）に譲 り，本解説記事では，ブロックチェーンの技術的インパ クトの理解を深めることを目的とし，2. でビットコイ ンのデー夕構造と権利移転機能の応用の一つとしての送 金の表現，3. で二重支払いや改ざんの問題に第三者を 介さずに対処するビットコインの巧妙な動作原理をそれ ぞれ解説し，その知識を元に 4. でブロックチェーン全 般の今後の応用や課題について触れる。読者のブロック チェーンに対する理解を，ビットコインの構造と動作原 理の理解を通して深めることができれば幸いである.

\section{データ構造と表現}

\section{1 秘密鍵で作る口座}

ビットコインには公開鍵のハッシュ值を文字列表現 したビットコインアドレスというものが存在する。例え 
ば,「1AlzP1eP5QGefi2DMPTfTL5SLmv7DivfNa」 は，ビットコイン上で初めて記録されたビットコインア ドレスである。 ビットコインアドレス $A$ は次のように 求まる.

$$
\begin{aligned}
& K=\text { '0x04',ECDSA }(k) \\
& A=\text { Base58Check('0x00',RIPEMD160 }(\operatorname{SHA} 256(K)))
\end{aligned}
$$

ここで， $k$ は 256bit の秘密鍵， $K$ は secp256k 1 をパ ラメータとする棈円曲線暗号を用いた署名アルゴリズム ECDSA の出力 5l2bit の前に 8bit のプレフィックスと して非圧縮を意味する 4 を追加した 520bit の公開鍵, Base58Check は入力にチェックサムを加えて人間が扱 いやすい文字列にエンコードする関数，RIPEMD160 と SHA256 は暗号学的ハッシュ関数である.

ビットコインアドレスは口座にたとえられる。田座の 基本的な要件である口座の開設は秘密鍵の生成，暗証番 号や銀行印は秘密鍵，口座番号は秘密鍵に対応するビッ トコインアドレスに相当する．ビットコインアドレスか らは秘密鍵を生成できないので, 送金先として安心して 公開できる。なお，秘密鍵は暗証番号や銀行印のような 気軽さでは変更できないため, 新たなビットコインアド レスを作って対応する，秘密鍵は誰でも自由に作成で き，誰が持っているかを記録することもないため，ビッ トコインアドレスの所有者の確認が困難である点は, 銀 行口座の要件とは大きく異なる点である.

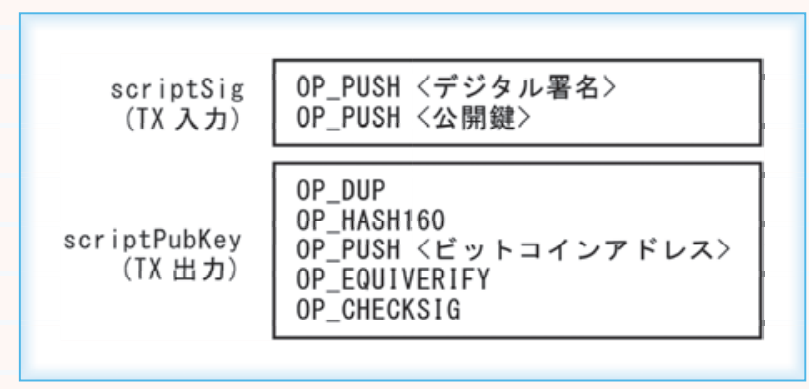

図 1 P2PKH 形式のスクリプト

\subsection{UTXO による残高の表現}

ビットコインの基礎となるデータ構造は, UTXO (Unspent transaction output) である. UTXO はビッ トコインの量と, scriptPubKey というフィールドを含ん でいる，ビットコインの量は最小単位である satoshi で 表現する. $10^{8}$ satoshi = 1 BTCである. scriptPubKey は, Locking Script とも呼ばれるスタックベースのス クリプトである.

2019 年 12 月現在, ビットコインのネットワーク上 には有効な UTXO が約 1 億個存在し, 誰でも読み取る ことができるが，誰でも使用できるわけではない，その ビットコインを使用できるのは, scriptPubKey の前方 に Unlocking Script とも呼ばれる scriptSig スクリプト を付け加えて実行した結果がTrue になるときに限る。

スクリプトには幾つかの慣例がある。 P2PKH（Pay to Public Key Hash) と呼ばれる形式を図 1 に示す. 動作手順の解説は文献（4）に譲るが，この二つのスク リプトを連結して実行した結果をTrue とするのは, scriptPubKey に指定されたビットコインアドレスに対 応する秘密鍵によるデイジタル署名と公開鍵を scriptSig に指定した場合のみである。すなわち，ビットコインア ドレス $A$ は対応する秘密鍵 $k$ を持つ者への支払先のよう に利用でき, scriptPubKey 内に $A$ を含む UTXO のビッ トコインの総和を $A$ の残高と表現できる。つまり，全て の残高は全て公開されており，この特徴は銀行の残高の 秘匿性の要件とは大きく異なるところである.

P2PKH 以外にも様々な表現が可能である．ビットコ インのスクリプトはチューリング完全ではないが, チューリング完全なプログラム（スマートコントラクト と呼ぶ）を記述可能な Ethereum に代表されるプラッ トホームも存在する.

\section{3 トランザクションによる送金の表現}

scriptPubKey の書かれた UTXO と，その使用権を主

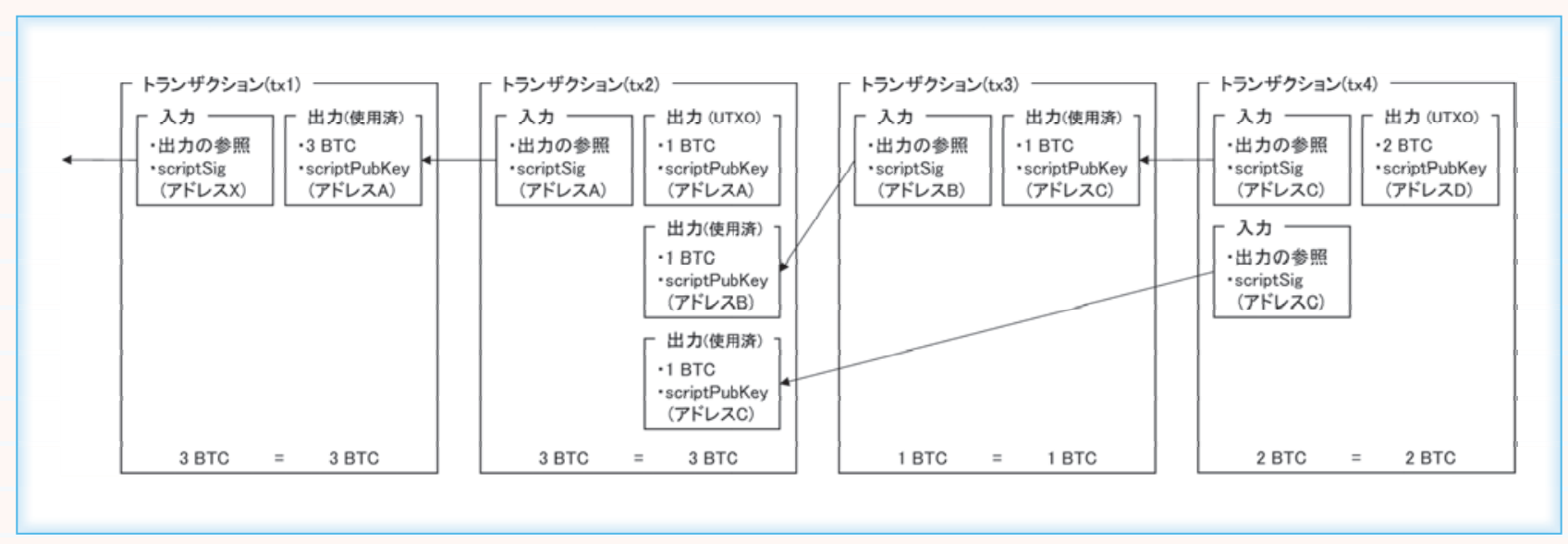


張する scriptSig は, それぞれ個別のトランザクション というデータ構造に記述される。 トランザクションは, 一つ以上の入力と出力を含み, 入力は UTXO への参照 と scriptSig, 出力は新規の UTXO である（図 2). 入 力の scriptSig が正しければ, 参照された出力は UTXO から使用済み出力へ変化する（図 2 の tx2 を参照, 矢 印は参照関係を示す).

トランザクションの出力のビットコインの総量は, 後 述の例外を除き，入力で参照した他のトランザクション の出力のそれを超えてはならないというルールがある. 一般的に送金は，送金元から引かれる額よりも送金先に 到達する額が増えてはならない要件があるが, この特徴 を用いれば，自分が使用できるUTXO のビットコイン の総量の範囲内で, 相手が使用できるUTXO を作るこ とでこの要件を満たし，ビットコインにおける送金を表 現できる。

例えば，図 2 の txl の作成時には UTXO が一つあり, ビットコインアドレス $A$ を含んだ scriptPubKeyが 3 BTCとともに存在していた。このとき，Aには 3 BTC の残高があるとみなされる。次に, $A$ の秘密鍵を持つ者 が tx2 を書いた。 入力の scriptSig が正しければ，参照 された txlの UTXO は使用済み出力となる. tx2 には UTXO が三つあり，それぞれビットコインアドレス $A$, $B, C$ を含んだ scriptPubKey が 1 BTC とともに存在し ている。これは, $A$ の 3 BTCを使って $B$ と $C へ 1$ BTC ずつ送金し，お釣りを $A$ に戻したことを意味し， $A, B$, $C$ それぞれに 1 BTC の残高があるとみなされる。同様 に tx3 は $B$ から $C$ へ 1 BTC 送金し, tx4 は $C$ から $D$ へ 2 BTC 送金したことを意味する。ここで, tx2 は一つの UTXO を分割し, tx4 は複数の UTXO を一つに統合し
た例であり，最終的に $A$ に 1 BTC，Dに 2 BTC の残高 があるとみなされる。

\section{4 ブロックチェーンによる履歴管理}

トランザクションは, ブロックと呼ばれるデータ構造 に書かれる。ブロックには，一つ以上のトランザクショ ンと, 一つ前のブロックへの参照が含まれている（図 3). ブロックの参照には ID を用いるが，ブロック内に は ID のフィールドはなく，ブロックのヘッダに対して 暗号学的ハッシュ関数を 2 回適用した值を ID として使 用する。

ブロック ID = SHA256（SHA256（ブロックヘッダ））

図 3 右下のように，ブロックは参照によって過去に 向かってつながった木構造となり得るが, 最終的には後 述の手法によってその中から 1 本のチェーンが選択さ れるような構造に収束することから，これをブロック チェーンと呼んでいる.

ブロック内のトランザクションを一部分でも書き換 えると, ヘッダに含まれるマークル木のルートハッシュ が変化し, 定義に従いそのブロックのIDも変化する. すると, その次のブロックが参照するブロック ID と不 一致になる。 よって, ブロック ID さえ保持しておけば, そのブロックまでに含まれる全てのトランザクションに 対して，後から改ざんされたかどうかを検証できる，送 金や残高の履歴管理の一般的な要件として求められる改 ざん検知はこのようにして実現されている.

また，全ての UTXO はブロック内のトランザクショ ンの出力に含まれている。 もう一つの要件として，それ らの履歴と最終的な残高の整合が取れていることが挙げ

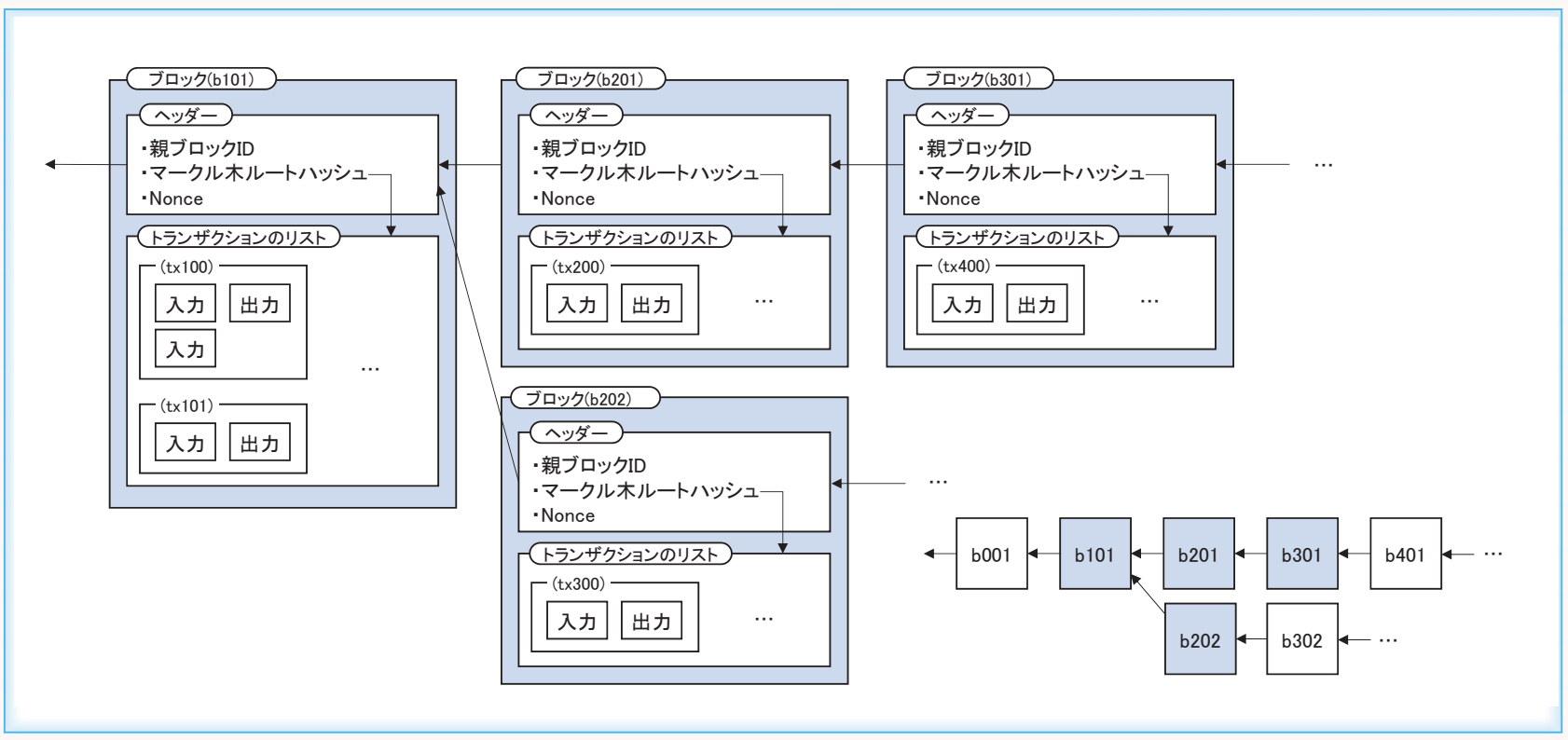


られるが，アドレスの残高や送金の履歴は，ブロック チェーンを最初から順番に読み取ってトランザクション 間の関係を追い掛けていくことで表現でき，誰にでも追 跡可能であり，その計算結果が現在の残高として表現さ れるのでそもそも整合を取る必要がなく，要件は満たさ れている。

2019 年 12 月現在, ビットコインのブロックチェー ンとして，60万個以上のブロックが存在している。初 めて作成されたブロックはgenesis ブロックと呼び, 2009 年 1 月に作られた。全てのブロックは, 過去に遡 ると必ず genesis ブロックにたどり着く。

\section{(3) 第三者を介さない仕組み}

\section{1 利用者が提供者にもなるシステム}

ビットコインには, 公式の実装も, 公式の Web サイ トも存在しないし, そもそも発案者のサトシ・ナカモト が誰なのかも分かっていない. そして, ビットコインの 仕組みそのものも, P2P (Peer-to-Peer) 技術を応用し, 徹底的に第三者に依存しないシステムになっている. P2P 技術は，第三者に相当する中央サーバやクラウド の代わりに，ノードが互いに同等な仲間（Peer）とし て接続し合うネットワーク構造を作り, 全体として一つ の目的を達成可能とする技術である。 ノードは参加も脱 退も自由だが，ネットワーク全体としては与えられた サービスを維持するように各ノードが協調動作する.

ビットコインはこの P2P 技術を応用し, サービスの 利用者としてのノードが，同時にサービスを提供する側 の一部に組み込まれるよう設計されている。あなたが ビットコインのプログラムを起動すると，世界のどこか で誰かが動かしているビットコインのプログラムと接続 する，そしてそのノードに他の接続先を聞いて，更に多 くのノードと接続する。こうして, あなたのノードも ビットコインのネットワークの一部として動作し始める. ブロックチェーンを構成するトランザクションなどの データは，このネットワーク内でコピーされて維持され る. 2019 年 12 月現在, 世界中で 1 万前後のノードに よって, ビットコインネットワークが維持されている.

\section{2 ビットコインが解決する重要な問題}

ここで，そのコピーされるトランザクションが全て同 一ではなく，悪意をもって本物とは異なったデー夕にし てコピーするノードがいたらどうなるだろうか. 例えば 図 4 にあるように，アドレス $A$ からあなたが所有する アドレス $B$ へ送金するトランザクションが入ったブロッ クYを見て，あなたは納得して $A$ の所有者へサービス を提供したとする。しかし $A$ の所有者はブロックをわ

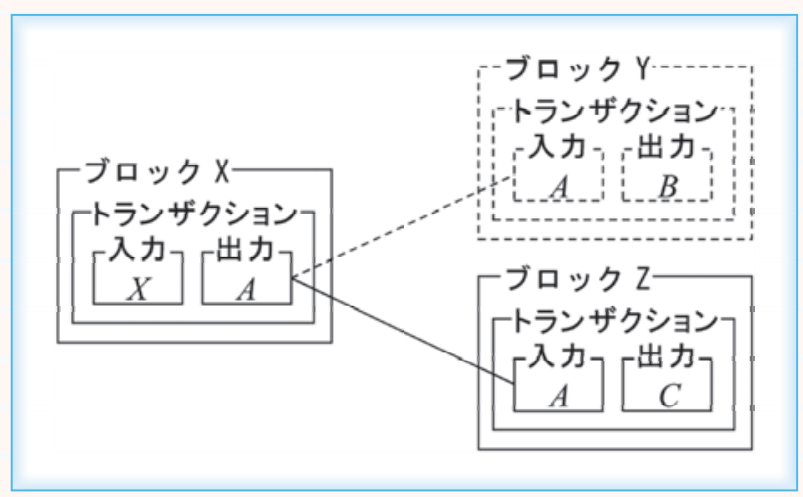

図 4 二重支払いの例

ざと二つに分岐させており，あなた以外には，あなた宛 に使われていたはずの UTXO を使って $C$ 宛に送金する トランザクションを含めたブロック Z を送信していた。 もしブロック Zが世界中に拡散するとそれが正しい履 歴となり, ブロック Y の方は無効となり, あなたは無 料でサービスを提供したことになってしまう.

これは，ネットワークを分割してブロックの追加（ね つ造）と削除（隠滅）を行った例であるが，時間差を 使ってもブロックの変更 (改ざん) を行うことができ る。例えば, あなたのノードが, ブロックYをいち早 く同期して手に入れたとする，その後，送金者はブロッ クYをブロック Z に改ざんしたとする。 あなたはその 検知ができてもその行為を止めることはできない. 同期 が遅れて改ざん後のコピーを初めて受け取ったノードか らすれば，ブロックZが正当に見える。こんなシステ ムでは安心して使うことができない.

この問題は「二重支払い問題」と呼ばれるが, 全ての ノードが一本に収束したブロックチェーンを全ての瞬間 で完全に同期して持っていれば解決する。だが，そんな ことを実現する方法がビットコインには実装されている のだろうか. 答えは現時点では「ノー」である. 現在の ビットコインは改ざんの定義を少し変えることで, この 問題を事実上解決している。

\section{3 ビットコインにおける悪意の定義}

システムとしてはデータの変更にすぎない操作が改 ざんと呼ばれるのは，そこに悪意が介在するからであ る. 第三者に紛争解決を求めることを放棄するならば, システムが人間の「悪意」を客観的な数值で判定し自動 的に解決しなければならないが, ビットコインは多数派 に反することを悪意とみなすこととした，木構造状に分 岐するブロックから多数派が 1 本のチェーンを選択す るとき，それ以外のチェーンの作成や選択はこの定義の おかげで悪意と判定できる。

多数派を決めるために, ビットコインではPoW (Proof of Work) ${ }^{(5),(6)}$ を用いる. ビットコインにおけ 
る PoW とは，ブロック ID が一定の範囲内に収まると きのブロックのヘッダの Nonce のことである. Nonce とは，ブロックヘッダに含まれる 4Byte の数值であり， 值そのものには意味を持たないが, Nonce が少しでも 変化するとブロック ID（前述のブロックヘッダを入力 として暗号学的ハッシュ関数を 2 回適用した值）が全 く違う值に変化する。暗号学的ハッシュ関数の特徴であ る原像困難性（与えられたハッシュ值に対応する入力を 見つけることが困難な性質）によって，条件に合う Nonce は条件を満たすまでその值を変化させながらブ ロック ID の計算を繰り返すよりほかに見つける方法が ない.

この性質により，そのブロック ID が一定の範囲内に 入っているときのブロックヘッダの Nonce は，その計 算をし続けたことの証明となる。与えられた Nonceが 条件に一致しているかは素早く検証できるが，条件に一 致する Nonce の発見には時間が掛かる。2019 年 12 月 現在, ビットコインのネットワーク全体がたたき出すこ とが可能な計算回数は毎秒 $10^{20}$ 回前後と推定されてお り，その力を持ってしても条件に合う Nonce を発見す るまでには平均 10 分ほど掛かる。（そうなるようにブ ロック ID の一定の範囲が自律的に調整される.)

ここで, 一つの興味深い現象が発生する。チェーンの 選択基準が同一なノード集合は，ノードのどれが Nonce を発見しても同じ基準のチェーンを選択するか ら，結果的に一つのグループとしてまとまっていくので ある. Nonceの発見は確率的なので同一グループのノー ドが同時に計算すると Nonce の発見も早まる。そのた め, 最大の計算能力の総和を持つグループが最も素早く チェーンを伸ばしていくことになる．結果として，ビッ トコインネットワークにおける多数派は, 同一のチェー ン選択基準を持った，計算能力の総和が最も大きいノー ドグループということになる．よって，安定して信用で きるビットコインネットワークを形成するには，チェー ンの選択基準を収束させることが重要となる。

\section{4 人間の欲望がチェーンを収束させる}

ブロックには入力のないトランザクションを含めら れるというルールがある. 出力量に一定の制限が存在す るが，ノードはUTXO を自分のアドレス宛にした入力 のないトランザクションをブロックに含めることで，そ のノードはビットコインを発行して自分で所持できる.

実はこのルールによって, 人間の欲望とチェーンの選 択基準がつながる。 大変な思いをして運良く Nonceを 発見し有効なブロックを作成したノードの運用者は，そ のブロックによってビットコインを発行した事実をより 強固にブロックチェーンに刻みたいと考えるのが自然で
ある.そのためには自分の作ったブロックの後ろに多数 のブロックが連なってほしいし，他のノードも同じ動機 で動いているという推測が働くので, 計算量が最も多く 注ぎ込まれかつ有効なデー夕構造を持った, 最も覆りに くいチェーンを選択し自分もその作成に寄与することが 基準となる，よって，少しでも多くの利益を得たい運用 者には，その基準で動作するノードを運用する動機が生 まれる。そして，その欲望は人間の大多数に共通してい るため，その選択基準が多数派となる.

こうして，ブロックチェーンの分岐が一時的に発生し たとしても，計算量が最も多く注ぎ込まれた有効な チェーンに収束し，それ以外のチェーンの選択は悪意で あるという基準がネットワークに安定的に生まれ，ノー ド間の紛争が自律的に解決される. 少数派がデータを改 ざんするために過去に遡って矛盾なくブロックチェーン をつなごうとしても，それを上回るスピードで多数派に よるブロックチェーンが成長するため，デー夕の改ざん が事実上不可能となる。 もちろん, 多数派を牛耳れば過 去のトランザクションの変更は可能だが, 多数派の全て のノードを特定の運用者が牛耳ることは事実上困難であ り，データの「変更」も事実上困難となる.

ブロックチェーンが正しく有効なブロックをつない でネットワーク全体で一つに収束することも, 改ざんが 事実上不可能となることも，ノードを運用する人間の利 益を得たいという欲望によって結果的に起こっている振 る舞いにすぎない. 人間の欲望が改ざんできないブロッ クチェーンを安定的に維持する力となって今も動き続け ているのであって，これは驚くべき事実である。

\section{これからのブロックチェーン}

\section{1 技術的な課題}

ブロックチェーンの技術的な課題として，スケーラビ リティはよく話題に挙がる。例えば，ビットコインが処 理できるトランザクションが実質的に 1 秒間に約 4 件 で頭打ちとなる問題があるが，これはブロックの承認頻 度が 10 分ごとでサイズ上限が 1MByte であることに原 因がある. Litecoin ${ }^{(7)}$ のようにブロックのサイズや承 認回数を増やせば処理性能は向上できるが，それと引換 えに改ざん耐性の劣化や DDoS 攻撃などのセキュリティ リスクが高まる。そこで，チェーンの選択基準 ${ }^{(8)}$ や, ネットワーク層の改善 ${ }^{(9)}$ を通して, セキュリティリス クを緩和する方法や，トランザクションのサイズを圧縮 する方法 ${ }^{(10),(11)}$ が提案されている.

また，エネルギー消費に関する議論も盛んである，例 えば，PoW のために全世界で大量のエネルギーが消費 されている問題がある ${ }^{(12),(13)}$. 現在のエネルギー消費 
の推計を可視化するサイトもあり ${ }^{(14)}$ ，これによれば 2019 年 12 月現在のビットコインネットワーク全体の消 費電力は約 $73 \mathrm{TW} \cdot \mathrm{h}$ ，全世界の電力消費の約 $0.3 \%$, 日 本の電力消費の約 $7.8 \%$ に相当する。この問題を解決す るため, PoW ではなく PoS (Proof of Stake) ${ }^{(15),(16)}$ と いう通貨の保有量や年齢の証明, PoI (Proof of Importance) ${ }^{(17)}$ という重要性の証明を活用してチェー ンを収束させるブロックチェーンを構築する動きがある が，これもセキュリティとのトレードオフの解決が課題 となっている.

セキュリティそのものの研究もある。例えば，量子コ ンピュータの発展により暗号学的ハッシュ関数や楕円曲 線暗号が危たい化し安全性が保たれなくなる問題への対 処を目指した，量子コンピュータに対する耐性を持った ブロックチェーンの研究がある ${ }^{(18),(19)}$. また, ビット コインには管理者がいないのでどの改善手法を選択する かは利用者次第であり，互換性のない実装を持ったノー ドが同時に存在しつづけた結果，恒久的にチェーンが分 岐するハードフォーク（Hard Fork）という現象が発生 することもある。これは悪意の定義が異なるネットワー クができたことを意味する，例えば，スケーラビリティ の改善手法に関する対立によってビットコインキャッ シュ (20) などの新たな暗号資産が誕生しており，これは 技術の発展や多様化の一現象である。また, The DAO の資金流出事件への対応で Ethereum の歴史を巻き戻 すために起こったハードフォーク ${ }^{(21)}$ は，第三者が強制 的に介入した改ざんという見方も，善意の資金流出を悪 意とみなす多数決によって善悪が変化したという見方も できる例である.

その他の話題も含めて最新情報を追うには，コミュニ ティの中でどのような議論がされているのかを知るのが 一番である。ビットコインの改善提案を行う場として BIP (Bitcoin Improvement Proposals) ${ }^{(22)}$ や，開発者 コミュニティの中でアイデアを議論できるメーリングリ スト ${ }^{(23)}$ などがインターネット上に存在する。 また，ブ ロックチェーン関連の各種ワークショップ (24), (25) もあ る.オンライン・オフラインで技術的な議論や人脈を形 成することも効果的な情報収集につながるだろう。

\section{2 ビットコイン以外への応用}

ビットコインのブロックチェーンとは, 人間の欲望に よってインターネットに浮かび上がったUTXO という 価值の塊，すなわちビットコインの価值そのものと表現 できるだろう。この価值をビットコイン以外へと一般化 し，分散型の信用基盤としてブロックチェーンを成立さ せるには，少なくとも次の三つが注意深く設計されてい ることが望ましい. (1)は2., (2)と (3)は3. で解説した
ビットコインが成立するための仕組みの本質に相当す る.

(1)扱うべき価值とその表現方法

(2)サービス利用者の活用すべき動機

(3)(1)と(2)から継続性や改ざん耐性への変換方法

有望な応用の一つに特許，著作権，登記などの権利管 理の自動化がある。権利はお金の価值と近く，人間には 権利を欲するという共通の動機があるため，ビットコイ ンのブロックチェーンと類似した設計で, 分散型の信用 基盤を構築できる可能性が高い.

ブロックチェーンを暗号資産以外に有効に応用でき た例はまだ少ない. ブロックチェーン活用をうたう実証 実験が散見されるが，新しい目的に適った分散型の信用 の設計が不完全で第三者の信用を部分的に借りる必要が あるか，そもそも目的が第三者の排除を前提としておら ず，ブロックチェーンではなくクラウド上に実装した方 が目的を効率的に達成できる場合が多い.

ブロックチェーンの良い応用例を生み出すには，ブ ロックチェーンの技術や性質をベースにアイデアを発想 するよりは，第三者を介さずに信用が分散して存在する 世界をベースに技術や常識抜きに発想したほうがよい. しかしそれは往々にして何らかの利権構造を破壊する結 果につながるので, サトシ・ナカモトに倣つてその導入 においても徹底的に第三者を排除する配慮が必要となる だろう。若しくは，最初は小さなコミュニティの中で楽 しく使うだけでもよいかもしれない. その有用性に気付 いたコミュニティの外の人たちよって肯定的に広く普及 していく可能性もあるからだ.

\section{文献}

(1) S. Nakamoto, "Bitcoin P2P e-cash paper," Nov.2008, https://www.mail-archive.com/ cryptography@metzdowd.com/msg09959.html

(2) S. Nakamoto, "Bitcoin: a peer-to-peer electronic cash system,” http://www.bitcoin.org/bitcoin.pdf

(3) A. M. Antonopoulos, "Mastering bitcoin: unlocking digital cryptocurrencies,” O'Reilly Media, Inc., Sebastopol, CA, 2014.

(4) https://en.bitcoinwiki.org/wiki/Pay-to-Pubkey_ Hash

(5) A. Back, "Hashcash - a denial of service countermeasure,” Aug.2002, http://www.hashcash.org/ hashcash.pdf.

(6) M. Jakobsson and A. Juels, "Proofs of work and bread pudding protocols," in Secure Information Networks, pp.258-272, Springer, Boston, MA, 1999.

(7) "Litecoin, open source P2P digital currency," https://litecoin.org

(8) Y. Sompolinsky and A. Zohar, "Secure high-rate transaction processing in bitcoin,” in International Conference on Financial Cryptography and Data 
Security, pp.507-527, Springer, Berlin, Heidelberg, 2015.

(9) I. Eyal, A. E. Gencer, E. G. Sirer, and R. Van Renesse, "Bitcoin-ng: a scalable blockchain protocol," 13th USENIX Symposium on Networked Systems Design and Implementation, pp.45-59, 2016.

(10) E. Lombrozo, J. Lau, and P. Wuille, "Segregated witness (consensus layer) ," https://github.com/ bitcoin/bips/blob/master/bip-0141.mediawiki

(11) J. Poon and D. Thaddeus, "The bitcoin lightning network: scalable off-chain instant payments," https://www.bitcoinlightning.com/bitcoinlightning-network-whitepaper/

(12) C. Stoll, L. Klaasen, and U. Gallersdorfer, "The carbon footprint of bitcoin,” Joule, vol.3, no.7, pp.1647-1661, July 2019.

(13) M. J. Krause and T. Tolaymat, "Quantification of energy and carbon costs for mining cryptocurrencies," Nature Sustainability, vol.1 no.11, pp.711-718, Nov. 2018.

(14) "Cambridge bitcoin electricity consumption index," https://www.cbeci.org

(15) “Nxt whitepaper," https://nxtwiki.org/wiki/ Whitepaper:Nxt

(16) S. King and S. Nadal, "PPCoin: peer-to-peer crypto-currency with proof-of-stake," https:// www.peercoin.net/whitepapers/peercoin-paper. pdf

(17) “NEM - Distributed ledger technology (Blockchain) - Harvesting \& poI,” https://nem. io/xem/harvesting-and-poi/
(18) K. Ikeda, "qBitcoin: a peer-to-peer quantum cash system," Science and Information Conference, pp.763-771, Springer, Cham, July 2018.

(19) E. O. Kiktenko, N. O. Pozhar, M. N. Anufriev, A. S. Trushechkin, R. R. Yunusov, Y. V. Kurochkin, A. I. Lvovsky, and A. K. Fedorov, "Quantumsecured blockchain," Quantum Science and Technology, vol.3 no.3, 035004, July 2018.

(20) https://www.bitcoincash.org

(21) V. Buterin, "Hard fork completed," https://blog. ethereum.org/2016/07/20/hard-fork-completed/, July 2016.

(22) “Bitcoin improvement proposals," https://github. com/bitcoin/bips

(23) https://lists.linuxfoundation.org/mailman/listinfo/ bitcoin-dev

(24) “Scaling bitcoin workshops," https:// scalingbitcoin.org/

(25) “Devcon,” https://devcon.org/

\section{小出俊夫 (正員)}

2004 創価大大学院博士後期課程 了. 博士 (工学). 同年 NEC 入社. OpenFlow 等の分散ネットワーク制 御の研究, 北米での OSS 開発を経 て，帰国後は IoT やブロックチェー ンの研究に従事. 2002 年度 C\&C 若手優秀論文賞, 平 16 年度本会学 術奨励賞, 2013 本会 ICM 研究専門 委員会 ICM 研究賞, 第 64 回電気科 学技術奖励賞各受賞。 